\title{
Risk of Multiple Sclerosis after Idiopathic Optic Neuritis in a Pakistani Population
}

\author{
Syed Faraz Kazim, Muhammad Islam, Mustafa Khan, Bilal Hameed, \\ Saad Shafqat
}

\begin{abstract}
Background and objective: Optic neuritis (ON) is associated with a 38\% ten-year risk of developing multiple sclerosis (MS) in Western populations, but the corresponding risk in non-Western populations is unclear. We conducted this study to estimate the risk of progression to MS after an episode of ON in a South Asian population. Methods: Two hundred and fifty-three patients with idiopathic $\mathrm{ON}$ were identified by reviewing records of visual evoked potentials and chart notes from a single academic center spanning the years 1990-2007. A structured telephone interview was then conducted to identify patients who had subsequently received a diagnosis of MS. The diagnosis was corroborated from chart notes, where possible. Cumulative probability of conversion to MS was calculated using Kaplan-Meier survival analysis. Results: The five-year risk of developing MS was $14.6 \%$ and the ten-year risk was $24 \%$. Patients $(\mathrm{N}=218)$ who had one or more typical demyelinating lesions on baseline brain magnetic resonance imaging (MRI) had a $68 \%$ 10-year risk; those with no lesions or non-typical lesions had a $14 \%$ risk $(\mathrm{p}<0.001)$. Female gender, recurrent ON, and occurrence of $\mathrm{ON}$ in winter months were also associated with increased risk ( $\mathrm{p} \leq 0.001)$. Severity of ON and likelihood of detecting cerebrospinal fluid (CSF) oligoclonal bands were higher in patients who developed MS. Conclusion: Idiopathic ON in Pakistan carries a lower risk of progression to MS compared with Western data. As in Western populations, however, presence of abnormal baseline brain MRI and CSF oligoclonal bands correlate with increased MS risk.
\end{abstract}

RÉSUMÉ: Risque de sclérose en plaques suite à une névrite optique idiopathique dans une population pakistanaise. Contexte et objectif : La névrite optique $(\mathrm{NO})$ est associée à un risque à dix ans de présenter une sclérose en plaques (SP) de $38 \%$ dans les populations occidentales. Ce risque est mal connu dans les autres populations. Nous avons effectué cette étude pour estimer le risque de progression vers une SP après un épisode de NO dans une population du sud de l'Asie. Méthodes : Deux cent cinquante-trois patients atteints de NO idiopathique ont été identifiés au moyen d'une revue de dossiers des potentiels évoqués visuels (PEV) et des notes cliniques recueillies entre 1990 et 2007 dans un centre universitaire. Les patients qui ont subséquemment reçu un diagnostic de SP ont été identifiés au moyen d'une entrevue téléphonique structurée. Le diagnostic était alors corroboré par les notes au dossier lorsque c'était possible. La probabilité cumulative de conversion vers une SP a ensuite été calculée au moyen de l'analyse de survie de Kaplan-Meier. Résultats : Le risque à 5 ans de présenter une SP était de $14,6 \%$ et à 10 ans de $24 \%$. Les patients $(\mathrm{N}=218)$, qui étaient porteurs de lésions démyélinisantes typiques (une lésion ou plus) à l'imagerie par résonance magnétique (IRM) du cerveau au départ, avaient un risque de $68 \%$ à 10 ans et le risque était de $14 \%(\mathrm{p}<0,001)$ chez ceux qui n'avaient pas de lésion ou des lésions non-typiques. Un risque plus élevé a été observé chez les femmes, les cas de NO récurrente et ceux chez qui la NO était apparue pendant les mois d'hiver $(\mathrm{p}<0,001)$. La sévérité de la NO et la probabilité de détecter des bandes oligoclonales étaient plus élevées chez les patients qui ont présenté subséquemment une SP. Conclusion : La NO idiopathique au Pakistan comporte un risque plus faible de progression vers une SP par rapport aux données obtenues en Occident. À l'instar des populations occidentales la présence d'anomalies à l'IRM cérébrale et de bandes oligoclonales dans le LCR initialement est corrélée à un risque accru de SP.

Can. J. Neurol. Sci. 2010; 37: 258-263

Optic neuritis $(\mathrm{ON})$ is an acute inflammatory disorder of the optic nerve frequently associated with concurrent or future multiple sclerosis (MS) ${ }^{1-6}$. Up to $20 \%$ of patients with MS initially present with an episode of $\mathrm{ON}$, and the condition occurs at some point during the course of illness in up to half of MS patients $^{6-8}$. In the Optic Neuritis Treatment Trial (ONTT), the risk of developing MS after an initial episode of ON was 30\% at 5 years, increasing to $38 \%$ at 10 years and $50 \%$ at 15 years $^{1-4}$. The ten year risk was significantly higher $(56 \%)$ in patients with one or more demyelinating lesions on a baseline magnetic resonance imaging (MRI) scan of the brain, as compared with $22 \%$ in those with no lesions ${ }^{2}$.

From the Section of Neurology (SFK, SS), Clinical Epidemiology Unit (MI), Clinical Neurophysiology Laboratory (MK, BH), Aga Khan University Hospital, Karachi, Pakistan.

Received June 11, 2009. Final Revisions Submitted September 2, 2009. Correspondence to: Saad Shafqat, Department of Medicine (Neurology), Aga Khan University Hospital, Stadium Road, Karachi 74800, Pakistan. 
Optic neuritis may result from a range of toxic, nutritional, metabolic, vascular, hereditary, infectious, infiltrative, autoimmune, or compressive etiologies. Idiopathic ON develops over hours to days in the absence of identifiable causes, and typically remits spontaneously ${ }^{9-11}$. Despite a number of prospective and retrospective studies conducted worldwide on the association of idiopathic ON with future risk of MS, there is a dearth of data from South Asia in general and Pakistan in particular ${ }^{12}$. We undertook this study primarily to estimate the risk of MS in patients presenting with idiopathic $\mathrm{ON}$ to a tertiary care hospital in Pakistan. A secondary aim was to identify additional factors associated with risk of MS.

\section{METHODS}

Study design: Primarily a retrospective-prospective study, it was conducted in two phases: (i) a retrospective medical record chart review; and (ii) a contemporary telephone interview. The study protocol was approved by our institution's Ethical Review Committee. Informed consent was obtained from all participants.

Case identification: Cases of $\mathrm{ON}$ were identified by searching the institution's medical record system based on ICD9-CM (International Classification of Diseases, 9th revision with clinical modification) coding and the visual evoked potentials (VEPs) database of our hospital's Clinical Neurophysiology Laboratory, covering an 18-year period (1990-2007).

Inclusion criteria: Adult patients (age $\geq 18$ years) with one or more episodes of idiopathic ON were included in the study. A diagnosis of $\mathrm{ON}$ by an ophthalmologist and/or a neurologist was a must for all patients. The end point was the development of MS based on diagnosis by a neurologist, or the end of the observation period. For the purposes of this study, patients who developed MS were classified as "MS converters," while those who did not were classified as "non-converters."

Exclusion criteria: Patients with $\mathrm{ON}$ attributable to an identifiable cause (toxic, nutritional, metabolic, vascular, hereditary, infectious, infiltrative, or autoimmune) were excluded. Patients with ON who developed neuromyelitis optica were also excluded from the study.

Chart review: Information on the following variables was extracted from laboratory and hospital records: patient age and gender; date of onset, laterality, signs and symptoms of ON; total number of $\mathrm{ON}$ episodes and interval between the first two episodes; cerebrospinal fluid (CSF) analysis, visual evoked potentials (VEPs) testing, and findings on brain MRI; and the treatment given for ON. Visual impairment was assessed using an ordinal scale described by Wingerchuk et $\mathrm{al}^{13}$ : $0=$ normal; $1=$ scotoma but visual acuity better than 20/30; $2=$ visual acuity of $20 / 30$ to $20 / 59$; $3=$ visual acuity of $20 / 60$ to $20 / 199$; $4=$ visual acuity of $20 / 200$ to $20 / 800 ; 5=$ counting fingers only; $6=$ light perception only; $7=$ no light perception; and $8=$ unknown visual acuity. The visual scores of both eyes were added to obtain the final visual acuity score. The MRI brain findings were recorded for the presence or absence of lesions; and in case of presence, the number, size, shape, and location of lesions were noted. Typical MRI brain lesions consistent with MS, based on ONTT and other clinical trials ${ }^{2,6,14}$, were defined as $\geq 1$ white matter lesions demonstrating one or more of the following characteristics: $\geq 3 \mathrm{~mm}$ in diameter, ovoid in shape, and located in the periventricular areas.
Telephone follow-up: Telephone contact was attempted for all cases. Patients were asked if they had received a diagnosis of MS from a neurologist in the interval since their episode of ON. Those answering "yes" were labeled as MS converters while those answering "no" or "not sure" were labeled as nonconverters. For those cases where such data was available, the diagnosis of MS was further corroborated from the hospital chart.

Data analysis: We used the Statistical Package for Social Sciences (SPSS) version 16.0 (C SPSS Inc., 1989-2007) for data entry and analysis. Continuous variables are reported as means ( \pm standard deviation), with median (and range) also shown in case of a skewed distribution. Pearson's chi-square test was used for comparison of proportions; the independent sample t-test or, for skewed distributions, the Mann-Whitney U test was used for comparison of means. Cumulative probability of conversion to MS, referred to as "risk" from here onward, was calculated using Kaplan-Meier survival analysis and the life table method and, where indicated, compared with the log rank test. For all comparisons, a p-value of $<0.05$ was considered statistically significant.

\section{RESUlTS}

A total of 703 patients with ON were identified from the institution's medical records and VEPs database. After filtering out cases of ON due to a secondary cause, 391 patients were left whose chart notes were considered complete with regards to the required baseline information. Of these, telephone contact could be established with 253 (response rate 64.3\%). Within this final study population, a subsequent diagnosis of MS had been made in 46 (absolute risk of conversion to MS, 18.2\%). Of the 138 patients in whom clinical follow-up data could not be obtained, 44 declined to be interviewed, 40 had invalid contact information, and in 54 there was no response despite multiple attempts at telephone contact. Of the 46 MS converters, the diagnosis was corroborated by chart notes in 25 patients; in the remaining 21 patients, it was based on their own verbal report that they had been given the diagnosis by a neurologist.

Table 1 compares patient characteristics across the two groups of converters and non-converters. The comparison shows that converters were significantly more likely to be women, experience $\mathrm{ON}$ during winter months, have more severe visual impairment, have recurrent $\mathrm{ON}$, report ocular pain, display optic disc swelling, have demyelinating lesions on baseline brain MRI, and have oligoclonal bands in baseline CSF examination. Converters were also significantly more likely to have experienced recurrent episodes of ON compared with nonconverters. The two groups of converters and non-converters were similar in several other variables, including mean age at ON onset, history of antecedent viral illness, bilateral ON, and initial treatment with intravenous versus oral corticosteroids.

Figure 1 shows the study population's Kaplan-Meier survival graph along with life table analysis for conversion to MS. The 5year risk of developing MS was $14.6 \%$ and the 10 -year risk was $24 \%$. Median time to diagnosis of MS was 4.5 years (range, 1-9 years) after the first episode of ON.

Baseline brain MRI data was available for 218 of the 253 study patients. Of these, $162(74.3 \%)$ had a normal MRI at the time of ON, while the MRI of the remaining 56 revealed one or 
Table 1: Demographic and clinical characteristics

\begin{tabular}{|c|c|c|c|}
\hline Variables & $\begin{array}{c}\text { MS } \\
\text { Converters } \\
(n=46) \\
\end{array}$ & $\begin{array}{c}\text { Non- } \\
\text { Converters } \\
(\mathbf{n}=\mathbf{2 0 7})\end{array}$ & P-value \\
\hline $\begin{array}{l}\text { Gender } \\
\text { Male } \\
\text { Female }\end{array}$ & $\begin{array}{l}13(28.3 \%) \\
33(71.7 \%)\end{array}$ & $\begin{array}{c}113(54.6 \%) \\
94(45.4 \%)\end{array}$ & $0.001 \ddagger$ \\
\hline Age (in years)* & $36.6 \pm 12.4$ & $37.8 \pm 12.9$ & 0.561 \\
\hline $\begin{array}{c}\text { History of viral illness } \\
\text { No } \\
\text { Yes } \\
\end{array}$ & $\begin{array}{c}37(80.4 \%) \\
9(19.6 \%)\end{array}$ & $\begin{array}{c}164(79.2 \%) \\
43(20.8 \%)\end{array}$ & 0.855 \\
\hline $\begin{array}{c}\text { Season of ON onset } \\
\text { Summer (Jun - Aug) } \\
\text { Autumn (Sep - Nov) } \\
\text { Winter (Dec - Feb) } \\
\text { Spring (Mar - May) } \\
\end{array}$ & $\begin{aligned} & 15(32.6 \%) \\
& 1(2.2 \%) \\
& 27(58.7 \%) \\
& 3(6.5 \%) \\
&\end{aligned}$ & $\begin{array}{l}55(26.6 \%) \\
66(31.9 \%) \\
55(26.6 \%) \\
31(15.0 \%) \\
\end{array}$ & $<0.001+$ \\
\hline $\begin{array}{c}\text { Eye involvement } \\
\text { Unilateral } \\
\text { Bilateral } \\
\end{array}$ & $\begin{array}{l}11(23.9 \%) \\
35(76.1 \%)\end{array}$ & $\begin{array}{c}77(37.2 \%) \\
130(62.8 \%)\end{array}$ & 0.087 \\
\hline $\begin{array}{c}\text { Ocular pain } \\
\text { No } \\
\text { Yes } \\
\end{array}$ & $\begin{array}{l}15(32.6 \%) \\
31(67.4 \%) \\
\end{array}$ & $\begin{array}{l}100(48.3 \%) \\
107(51.7 \%)\end{array}$ & $0.037 \$$ \\
\hline $\begin{array}{c}\text { Visual Field Defect } \\
\text { No } \\
\text { Yes } \\
\end{array}$ & $\begin{array}{l}23(50.0 \%) \\
23(50.0 \%)\end{array}$ & $\begin{array}{c}151(72.9 \%) \\
56(27.1 \%)\end{array}$ & $0.002+$ \\
\hline $\begin{array}{c}\text { Optic Disc Swelling } \\
\text { No } \\
\text { Yes } \\
\end{array}$ & $\begin{array}{l}17(37.0 \%) \\
29(63.0 \%) \\
\end{array}$ & $\begin{array}{c}110(53.1 \%) \\
97(46.9 \%) \\
\end{array}$ & $0.047 t$ \\
\hline $\begin{array}{l}\text { Visual Acuity }{ }^{*} \\
\text { (Left }+ \text { Right) }\end{array}$ & $4.1(2.0)$ & $3.5(2.5)$ & $0.043+$ \\
\hline $\begin{array}{c}\text { Total No. of ON } \\
\text { episodes } \dagger\end{array}$ & $3.0(2.0-4.0)$ & $1.0(1.0-6.0)$ & $<0.001+$ \\
\hline $\begin{array}{l}\text { Interval between first } \\
\text { two episodes of ON } \\
\text { (in months) } \dagger\end{array}$ & $11.5(2-36)$ & $14.5(1-50) \S$ & N/A \\
\hline
\end{tabular}

Abbreviations: MS, multiple sclerosis; ON, Optic neuritis; N/A, Not applicable; Values are expressed as number (percentage) of patients; $*$ Mean \pm Standard deviation; $\dagger$ Median (Range); $\$$ Statistically significant; $\S$ Only 36 out of 207 non-converters had more than one episode of ON.

more typical demyelinating lesions. The latter group had a $68 \%$ ten-year cumulative risk of developing MS, while the corresponding risk in patients with normal scans was $14 \%$ ( $p<0.001$ by log rank test). Table 2 shows the distribution of MS converters and non-converters with regards to MRI findings on initial presentation. Figure 2 depicts the Kaplan-Meier survival graph for conversion to MS in patients with and without typical demyelinating lesions.

Cerebrospinal fluid data was available in 118 of the 253 study patients. Oligoclonal bands were observed more frequently in MS converters versus non-converters (16 of 35 or $45.7 \%$ versus 11 of 90 or $12.2 \%$, respectively; $\mathrm{p}=0.004)$. The remaining CSF variables, including glucose and protein concentrations, and total leukocyte count, did not differ between converters and nonconverters. History of corticosteroid treatment did not differ significantly between converters and non-converters $(\mathrm{p}=0.283)$. There was also no statistically significant difference in the conversion rate to MS between those patients treated with intravenous steroids followed by oral steroids versus those who received oral steroids alone ( 25 of 129 or $19.4 \%$ versus 15 of 84 or $17.9 \%$, respectively; $\mathrm{p}=0.408$ ). Table 3 depicts the effect of steroid treatment at initial presentation on the outcome of $\mathrm{ON}$.

When the data of those patients with whom we were able to establish the telephone-based follow-up ( $n=253$, referred to as "responders" from here onwards) was compared with those with whom no contact could be established $(n=138$, referred to as "non-responders" from here onwards), there was no significant difference in terms of age $(36.6 \pm 12.4$ years in responders versus $35.1 \pm 12$ years in non-responders; $\mathrm{p}=0.43)$, gender ( $49.8 \%$ males among responders versus $48.6 \%$ males among non-responders; $\mathrm{p}=0.211)$, laterality of $\mathrm{ON}(34.8 \%$ unilateral among responders versus $31.9 \%$ unilateral among non-responders; $\mathrm{p}=0.34)$, or abnormal baseline brain MRI $(25.7 \%$ abnormal among responders versus $25.5 \%$ abnormal among non-responders; $\mathrm{p}=0.36$ ). However, the difference in the number of patients with recurrent $\mathrm{ON}$ between responders and non-responders was approaching statistical significance $(30.5 \%$ versus $29.7 \%$; $\mathrm{p}=0.06)$.

\section{Discussion}

The ONTT, a prospective multi-center study of 388 patients with optic neuritis who did not have probable or definite MS at the time of enrolment, reported the risk of developing MS after

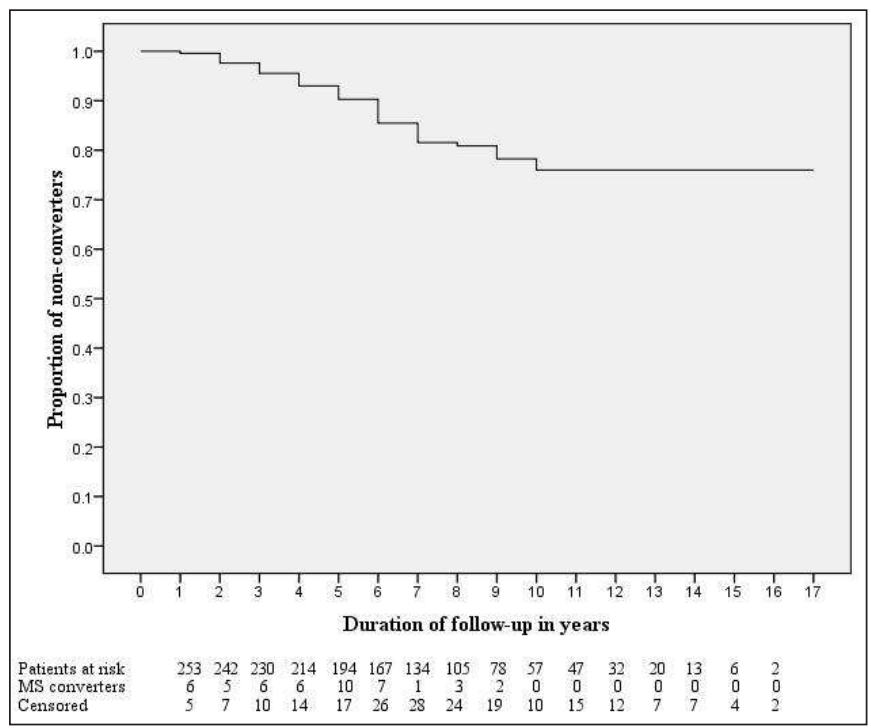

Figure 1: Kaplan-Meier curve showing the cumulative probability of conversion to multiple sclerosis (MS) after an initial episode of idiopathic optic neuritis (five-year risk, 14.55\%; ten-year risk, 24\%). The number of patients exposed to risk is those patients who have not developed MS at the beginning of each year. The MS converters are those patients who developed multiple sclerosis during each year. The "censored" rows depict those patients who did not develop multiple sclerosis and their follow-up period ended during each yearly interval. 
Table 2: Brain magnetic resonance imaging (MRI) findings at initial presentation

\begin{tabular}{l|c|c|c}
\hline \multicolumn{4}{c}{ End point } \\
\hline MRI findings $\dagger+$ & $\begin{array}{c}\text { MS } \\
\text { converters }\end{array}$ & $\begin{array}{c}\text { Non- } \\
\text { converters }\end{array}$ & Total \\
\hline Abnormal $(n=56)$ & $29(51.8)$ & $27(48.2)$ & 56 \\
\hline Normal $(n=162)$ & $14(9.3)$ & $148(90.7)$ & 162 \\
\hline
\end{tabular}

Abbreviations: MRI=Magnetic resonance imaging, $\mathrm{MS}=$ Multiple sclerosis; Values are expressed as number (percentage) of patients.

$\dagger$ Initial MRI brain was done in 218 patients; $¥$ Typical MRI brain lesions consistent with MS $(P<0.001, \log$ rank test $)$. Typical MRI brain lesions consistent with MS, based on optic neuritis treatment trial (ONTT) and other clinical trials ${ }^{2,6,14}$, were defined as $\geq 1$ white matter lesions demonstrating one or more of the following characteristics: $\geq 3 \mathrm{~mm}$ in diameter, ovoid in shape, and located in the periventricular areas.

an episode of $\mathrm{ON}$ as $30 \%$ at 5 years, $38 \%$ at 10 years, and $50 \%$ at 15 years $^{1-4}$. In a prospective study from Sweden, SandbergWollheim et al showed that the cumulative probability of developing MS within 15 years of an initial episode of ON was $45 \%{ }^{5}$. In a series of 60 patients from New England, Rizzo and Lessell ${ }^{15}$ reported that $74 \%$ of the women and $34 \%$ of the men in their study developed MS within 15 years of an initial attack of ON. A conclusion common to all these studies is that the cumulative conversion rate increases more rapidly during the initial ten years after which it continues to rise, albeit more slowly. Söderström et al in a population-based study of 147 consecutive patients of acute ON in Stockholm, Sweden, reported that 53 patients (36\%) developed MS during a 15 year follow-up period ${ }^{16}$. Compared with studies from other regions, our data (five-year risk, 14.55\%; ten-year risk, 24\%) shows a lower risk of MS after ON. However, these risks are comparable to those reported from Taiwan (cumulative probability $5.9 \%$ at two years and $14.3 \%$ at five years) and Brazil (nine-year risk $10.8 \%)^{17,18}$.

There is scant data on the risk of MS in Pakistan. The prevalence of MS varies considerably in Asian countries but in general is believed to be less than in Caucasian populations ${ }^{12}$.



Figure 2: The cumulative probability of multiple sclerosis (MS) was statistically significantly higher in patients with one or more typical demyelinating lesions seen on baseline magnetic resonance imaging (MRI) scan of the brain than in patients with no lesions and non-typical lesions $(p<0.001, \log$ rank test). Typical MRI brain lesions consistent with MS, based on optic neuritis treatment trial (ONTT) and other clinical trials ${ }^{2,6,14}$, were defined as $\geq 1$ white matter lesions demonstrating one or more of the following characteristics: $\geq 3 \mathrm{~mm}$ in diameter, ovoid in shape, and located in the periventricular areas.

Both genetic and environmental factors may underlie the relatively low Asian conversion rates to MS after ON. Singhal et $\mathrm{al}^{19,20}$ have commented that Indian patients with MS are more akin to those reported from Japan and other Asian countries as compared to Western populations. Alternatively, differences in risk estimates across various studies may also be attributed to methodological issues such as the retrospective or prospective nature of the study, single- or multi-center data collection, etc.

The presence of typical demyelinating lesions on brain MRI at initial presentation was the strongest predictor of developing MS in our study. However, a number of patients $(n=14)$ with an

Table 3: Effect of steroid treatment at initial presentation

\begin{tabular}{c|c|c|c|c|c}
\hline Outcome & $\begin{array}{c}\text { IV+PO } \\
(\mathbf{n = 1 2 9})\end{array}$ & $\begin{array}{c}\mathbf{I V} \\
(\mathbf{n}=\mathbf{1 9})\end{array}$ & $\begin{array}{c}\text { PO } \\
(\mathbf{n = 8 4})\end{array}$ & $\begin{array}{c}\text { No treatment } \\
(\mathbf{n}=\mathbf{2 1})\end{array}$ & Total \\
\hline MS & $25(19.4)$ & $4(21)$ & $15(17.9)$ & $2(9.5)$ & 46 \\
\hline No MS & $104(81.6)$ & $15(79)$ & $69(82.1)$ & $19(91.5)$ & 207 \\
\hline
\end{tabular}

Abbreviations: IV, intravenous methylprednisolone treatment; PO, oral prednisone treatment; IV+PO, intravenous followed by oral corticosteroids; MS, Multiple sclerosis. Values are expressed as number (percentage) of patients. 
initially normal MRI also went on to develop MS. In the $\mathrm{ONTT}^{2,4}$, patients with one or more typical lesions on baseline MRI had a $56 \%$ ten-year risk and a $72 \% 15$-year risk of future MS. This is comparable to the $68 \%$ ten-year risk in the corresponding subset in our sample. Söderström et al ${ }^{16}$ reported that the presence of three or more MS-like MRI lesions was strongly associated with the development of MS $(\mathrm{p}<0.001)$. Lin et $\mathrm{al}^{17}$ in their study from Taiwan also identified central nervous system imaging abnormalities as risk indicators for the development of MS $(\mathrm{p}<0.05)$. There is a consensus between studies done both in Western and Eastern countries regarding the higher risk of MS with typical demyelinating lesions on baseline MRI of the brain. Our study further corroborates the evidence.

Younger age has traditionally been associated with greater MS risk ${ }^{5}$. However, there was no statistically significant difference in age between MS converters and non-converters in our study. We found the risk of conversion to MS to be higher among females, consistent with observations from ONTT $^{1-4}$ as well as other studies ${ }^{5}$. Previous studies have also reported an effect of seasonal variation on outcomes after $\mathrm{ON}^{1,5,21}$. Our finding of a higher risk of MS in patients who had their initial $\mathrm{ON}$ episode during winter months is congruent with previous reports. A history of viral illness at the onset of $\mathrm{ON}$ has been reported to carry an increased risk of future $\mathrm{MS}^{22}$. Bansil et $\mathrm{al}^{23}$ have also suggested an environmental disease triggering agent for MS in Indian patients. However, we found no significant difference in this variable between the MS converters and nonconverters in our study.

Our results showed a strong relationship between the number of ON episodes and future MS risk, with $100 \%$ converters having experienced recurrent events, but only $17.4 \%$ of the nonconverters. Pirko et $\mathrm{al}^{9}$ in a study of the natural history of recurrent $\mathrm{ON}$ have reported that patients with a rapid succession of severe $\mathrm{ON}$ events are more likely to develop a generalized demyelinating disorder. Sandberg-Wollheim et $\mathrm{al}^{5}$ have also reported similar findings. Classically, monocular acute demyelinating $\mathrm{ON}$ has been associated with $\mathrm{MS}^{6}$; however, we found no significant difference between unilateral and bilateral ON with regards to future MS risk.

The presence of oligoclonal bands on CSF electrophoresis has been associated with a higher risk of $\mathrm{MS}^{5,21}$. Our data also showed a very strong association between the presence of CSF oligoclonal bands and future MS risk. Although CSF pleocytosis has been reported to be associated with a higher risk of $\mathrm{MS}^{24}$, we found no significant association in our analysis.

In patients with acute $\mathrm{ON}$, treatment with a three-day course of high-dose intravenous methyl prednisolone followed by a short course of oral prednisone has been shown to reduce the rate of developing $\mathrm{MS}^{25}$. However, in the ONTT, the benefits of intravenous methyl prednisolone did not persist beyond two years. Our data also showed no significant effect of intravenous methyl prednisolone followed by oral prednisone versus oral prednisone alone on the long-term outcome of ON.

\section{LIMITATIONS}

Our study has certain limitations and the results need to be interpreted in a prudent manner. Cases of ON were retrospectively identified and their associated findings abstracted from routine hospital records, whose accuracy is subject to the inherent variability of clinical documentation. Nonetheless, we excluded incomplete chart notes from the study sample. Our study presents data from a single center, thus there are chances of potential referral bias. Nevertheless, our hospital has a wide catchment both geographically and across social strata, so the probability of spectrum bias may not be significant. We identified our cases both from our VEPs database as well as chart records to make sure that we do not miss any case of $\mathrm{ON}$ treated at our hospital during the period of interest. Not all patients of $\mathrm{ON}$ at our center undergo VEPs testing, however. Despite making every effort to exclude secondary cases of $\mathrm{ON}$, the retrospective nature of our study cannot exclude the possibility that some cases of secondary ON may have been misclassified as idiopathic. Our analysis is based on the 253 cases who were contactable for contemporary follow-up; this excludes 138 identified cases of $\mathrm{ON}$ in whom we were unable to obtain followup information, either due to refusal to be interviewed, or inadequate or unavailable contact information. This could have led to underestimation of the cumulative probability of MS converters, especially considering the fact that 41 out of 138 non-responders have recurrent $\mathrm{ON}$ and 25 out of 98 had typical demyelinating lesions on baseline MRI brain. Still, there is no $a$ priori reason to assume that it would have biased the evaluation of prognostic factors. Finally, 21 of the $46 \mathrm{MS}$ converters in our study were so classified based on patients' self-report obtained via telephone. In each case, the diagnosis had been made by a neurologist. Ideally, this self-report should be independently validated, but we lacked the resources to overcome this practical limitation.

\section{Conclusions}

We note that ON patients in Pakistan have lower rates of conversion to MS in comparison with Western figures. Features associated with augmented risk are similar to Western reports, however, and include female gender, abnormal baseline brain MRI, presence of CSF oligoclonal bands, onset in winter months, and recurrent $\mathrm{ON}$ episodes. The rate of conversion did not differ among the different treatment groups. Our results are relevant to clinical practice because they reinforce the strong prognostic value of baseline brain MRI in patients with idiopathic ON. These findings also reaffirm the importance of genetic and/or environmental differences underlying variable MS risk around the world. We believe these data justify the need for a large prospective study of $\mathrm{ON}$ in Pakistani patients.

\section{ACKNOWLEDGEMENT}

The authors thank Mr. Tasneem Khan, assistant manager in the Department of Medicine at our hospital, for assistance in telephone follow-ups.

\section{ETHICAL APPROVAL}

Ethical approval for the study was obtained from the Ethics Review Committee at Aga Khan University, Karachi, Pakistan through application number 630-MS/ERC-06.

\section{FUNDING}

Funding for this study was provided by the Section of Neurology, Aga Khan University Hospital, Karachi, Pakistan. 


\section{REFERENCES}

1. Optic Neuritis Study Group. The 5-year risk of MS after optic neuritis: experience of the optic neuritis treatment trial. Neurology. 1997;49(5):1404-13.

2. Beck RW, Trobe JD, Moke PS, Gal RL, Xing D, Bhatti MT, et al. High- and low- risk profiles for the development of multiple sclerosis within 10 years after optic neuritis: experience of optic neuritis treatment trial. Arch Ophthalmol. 2003;121(7):944-9.

3. Beck RW, Smith CH, Gal RL, Xing D, Bhatti MT, Brodsky MC, et al. Neurologic impairment 10 years after optic neuritis. Arch Neurol. 2004;61(9):1386-9.

4. Optic Neuritis Study Group. Multiple sclerosis risk after optic neuritis: final optic neuritis treatment trial follow-up. Arch Neurol. 2008;65(6):727-32.

5. Sandberg - Wollheim M, Bynke H, Cronqvist S, Holtas S, Platz P, Ryder LP. A long-term prospective study of optic neuritis: evaluation of risk factors. Ann Neurol. 1990;27(4):386-93.

6. Balcer LJ. Clinical practice. Optic neuritis. N Engl J Med. 2006; 354(12):1273-80.

7. Arnold AC. Evolving management of optic neuritis and multiple sclerosis. Am J Ophthalmol. 2005;139(6):1101-8.

8. Frohman EM, Frohman TC, Zee DS, McColl R, Galetta S. The neuro-ophthalmology of multiple sclerosis. Lancet Neurol. 2005; 4(2):111-21.

9. Pirko I, Blauwet LK, Lesnick TG, Weinshenker BG. The natural history of recurrent optic neuritis. Arch Neurol. 2004;61(9): 1401-5.

10. Rodriguez M, Siva A, Cross SA, O’Brien PC, Kurland LT. Optic neuritis: a population-based study in Olmsted County, Minnesota. Neurology. 1995;45(2):244-50.

11. Optic Neuritis Study Group. The clinical profile of acute optic neuritis: experience of the Optic Neuritis Treatment Trial. Arch Ophthalmol. 1991;109(12):1673-8.

12. Wasay M, Khatri IA, Khealani B, Sheerani M. MS in Asian countries. Int MS J. 2006;13(2):58-65.

13. Wingerchuk DM, Hogancamp WF, O'Brien PC, Weinshenker BG. The clinical course of neuromyelitis optica (Devic's syndrome). Neurology. 1999;53(5):1107-14.
14. CHAMPS Study Group. Interferon beta-1a for optic neuritis patients at high risk for multiple sclerosis. Am J Ophthalmol. 2001;132(4):463-71

15. Rizzo J F 3rd, Lessell S. Risk of developing multiple sclerosis after uncomplicated optic neuritis: a long-term prospective study. Neurology. 1988;38(2):185-190.

16. Söderström M, Ya-Ping J, Hillert J, Link H. Optic neuritis: prognosis for multiple sclerosis from MRI, CSF, and HLA findings. Neurology. 1998;50(3):708-14.

17. Lin YC, Yen MY, Hsu WM, Lee HC, Wang AG. Low conversion rate to multiple sclerosis in idiopathic optic neuritis patients in Taiwan. Jpn J Ophthalmol. 2006;50(2):170-5.

18. Lana-Peixoto MA, Lana-Peixoto MI. The risk of multiple sclerosis developing in patients with idiopathic optic neuritis in Brazil. Arq Neuropsiquiatr. 1991;49(4):377-83.

19. Singhal BS. Multiple sclerosis - Indian experience. Ann Acad Med Singapore. 1985; 14(1):32-6.

20. Singhal BS. Multiple sclerosis. Neurol India. 1999;47(1):1-2.

21. Nilsson P, Larsson E M, Maly - Sundgren P, Perfekt R, Sandberg Wollheim M. Predicting the outcome of optic neuritis: evaluation of risk factors after 30 years of follow-up. J Neurol. 2005;252(4): 396-402.

22. Tumani H, Tourtellotte WW, Peter JB, Felgenhauer K. Acute optic neuritis: combined immunological markers and magnetic resonance imaging predict subsequent development of multiple sclerosis. The Optic Neuritis Study Group. J Neurol Sci. 1998; 155(1):44-9.

23. Bansil S, Singhal BS, Ahuja GK, Riise T, Ladiwala U, Behari M, et al. Multiple sclerosis in India: a case-control study of environmental exposures. Acta Neurol Scand. 1997;95(2):90-5.

24. Stendahl-Brodin L, Link H. Optic neuritis: oligoclonal bands increase the risk of multiple sclerosis. Acta Neurol Scand. 1983; 67(5):301-4.

25. Beck RW, Cleary PA, Trobe JD, Kaufman DI, Kupersmith MJ, Paty DW, et al. The effects of corticosteroids for acute optic neuritis on the subsequent development of multiple sclerosis. N Engl J Med. 1993;329(24):1764-9. 